\section{Cost awareness on the part of health professionals}

To the Editor: The African region bears more than $24 \%$ of the global burden of disease, but has access to less than $1 \%$ of the financial resources. ${ }^{[1]}$ Access to healthcare is a significant concern in South Africa (SA), and financial cost is a recognised cause of lack of access to adequate healthcare. Furthermore, increasing healthcare costs affect healthcare decisions taken by poorer households, further decreasing their already limited access. ${ }^{[2]}$ Resource scarcity also determines the standard of care, and higher costs have been shown to have a negative impact on patient outcomes. ${ }^{[3]}$ The cost of healthcare can also affect other aspects of living, and for some members of society can mean the choice between medication and essentials of living such as food. ${ }^{[4]}$

In 2012, SA government expenditure on healthcare amounted to $8.8 \%$ of the GDP. ${ }^{[5,6]}$ Compared with other countries of similar development status and some high-income countries, SA's level of spending is high but health status indicators are much worse, ${ }^{[5]}$ suggesting that equitable and efficient resource utilisation is still a major challenge. In terms of healthcare spending per capita, SA ranks below higher-income countries with a spending of USD982 per person per year in 2012 (calculation based on purchasing power parity), compared with the Organisation for Economic Co-operation and Development (OECD) average of USD3 484 per person per year. ${ }^{[6]}$

The costs of providing medical care are not only high but are escalating, and several measures have been suggested and employed to reduce these expenses. ${ }^{[3]}$ Anstey et al. ${ }^{[7]}$ recently suggested a framework focusing on Talking to patients about their preferences for care, Asking for outside tests, Avoiding Routine and/or Repeated tests, prescribing Generic medications, Education about costs, and appropriate Transfusion practices (TARGET) to reduce intensive care unit costs. In our public health setting in SA, choices such as which medicines to prescribe are limited. However, in-depth teaching of cost awareness may prove to be an important step in overcoming one of the biggest challenges of the SA health system, lack of resources. It is easy for managers to obtain information on the costs of drugs, equipment, disposables, tests and other expendables that healthcare professionals use in their practice, and it is just as easy to make such information readily available to healthcare workers.

As the public health system is faced with increasing budget constraints, healthcare professionals are in a position to act as stewards in ensuring that healthcare provision is effectively utilised and cost-effective. Providers have an influence on total spending and allocation of limited healthcare resources, and they can act as drivers in the effort to contain costs.

Unfortunately studies done in less resource-limited environments have found that medical professionals have limited understanding of the costs of medical care, and that their knowledge and awareness of costs and the implications thereof are limited. ${ }^{[4,8-11]}$

Glickman et al. ${ }^{[4]}$ in a survey done in the USA on doctors' knowledge of drug costs found a trend towards underestimation of the prices of expensive drugs and overestimation of the prices of less expensive drugs. Estimates of prices by doctors were also highly variable; younger doctors were more likely than older ones to make correct estimates, and specialists in internal medicine were less likely to make correct estimates than specialists from other disciplines.

A more recent systematic review on doctors' awareness of drug costs showed a similar pattern. ${ }^{[3]}$ Awareness of costs was lacking, and doctors tended to underestimate the costs of expensive drugs and overestimate the costs of less expensive ones. In addition, doctors in this study indicated that they wanted cost information but found it inaccessible - an unnecessary, highly undesirable and easily remedied situation.

Predictors of cost awareness among healthcare staff also vary. Most studies indicate that there is no difference in cost estimation accuracy between health professionals at various levels of training and experience, with a number of studies finding no difference in cost estimation accuracy among medical students, residents, faculty doctors, specialists and doctors from different practice settings, nurses and ward clerks, suggesting that health science education as it currently stands, as well as experience or involvement in private practice, does not significantly influence awareness of costs. ${ }^{[4,12-14]}$

Over-ordering tests, additional costs related to wastage and mishandling of disposables and equipment contribute to escalating healthcare costs, and initiatives and interventions to minimise these costs may reduce expenditure and are particularly pertinent in a setting where resources are limited. Cost-awareness strategies may allow for improved resource management, and may prevent wasteful expenditure through the ordering of unnecessary investigations, tests and therapies. They would enable healthcare workers to be conscious of absolute costs as well to make comparisons between different products and therapies. Staff knowledge of costs also informs the decisions that lead to the most cost-effective treatment options being chosen.

The ability to make a correct estimation has, unsurprisingly, been associated with the ordering of fewer tests. ${ }^{[14]}$ The concern that this may negatively affect outcome is unsubstantiated, although it is a topic that requires further investigation; however, strategies to improve healthcare awareness of costs have been shown to reduce costs. Unfortunately, data describing SA healthcare practitioners' awareness of costs are lacking, and availability of such information may aid educators and other decision-makers in improving strategies aimed at cost-awareness training.

\section{Gladness Dakalo Nethathe}

Intensive Care Unit, Chris Hani Baragwanath Academic Hospital, Johannesburg, South Africa, and Division of Critical Care, Faculty of Health Sciences, University of the Witwatersrand, Johannesburg

gladness.nethathe@wits.ac.za

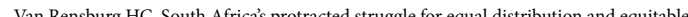

not there. Hum Resour Health 2014;12(1):26. [http://dx.doi.org/10.1186/1478-4491-12-26]

Castro-Leal F, Dayton J, Demery L, Mehra K. Public spending on health care in Africa: Do the poor benefit? Bull World Health Organ 2000;78(1):66-74

Allan GM, Lexchin J, Wiebe N. Physician awareness of drug cost: A systematic review. PLoS Med 2007;4(9):e283. [http://dx.doi.org/10.1371/journal.pmed.0040283]

4. Glickman L, Bruce EA, Caro FG, Avorn J. Physicians' knowledge of drug costs for the elderly. J Am Geriatr Soc 1994;42(9):992-996. [http://dx.doi.org/10.1111/j.1532-5415.1994.tb06594.x]

World Health Organization. National health accounts. http://www.who.int/nha/country/ZAF.pdf (accessed 31 January 2015).

6. Organisation for Economic Co-operation and Development. OECD Health Statistics 2014. How does South Africa compare? http://www.oecd.org/els/health-systems/Briefing-Note-SOUTH-AFRICA-2014. pdf (accessed 31 January 2015).

7. Anstey $\mathrm{MH}$, Weinberger SE, Roberts $\mathrm{DH}$. Teaching and practicing cost-awareness in the intensive care unit: A TARGET to aim for. J Crit Care 2014;29(1):107-111. [http://dx.doi.org/10.1016/j. jerc unit: A TARG

Schilling

W. Cost awareness among Swedish physicians working at the emergency department. Eur I Emerg Med 2009;16(3):131-134. [http://dx.doi.org/10.1097/MEJ.0b013e32831cf605]

. Miller LG, Blum A. Physician awareness of prescription drug costs: A missing element of drug advertising and promotion. J Fam Pract 1993;36(1):33-36.

10. Bade K, Hoogerbrug J. Awareness of surgical costs: A multicenter cross-sectional survey. J Surg Educ 2015;72(1):23-27. [http://dx.doi.org/10.1016/j.jsurg.2014.06.017]

11. Allan GM, Innes G. Family practice residents' awareness of medical care costs in British Columbia. Fam Med 2002;34(2):104-109.

2. Fowkes F. Doctor knowledge of the costs of medical care. Med Educ 1985;19(2):113-117. [http://dx.doi. org/10.1111/j.1365-2923.1985.tb01150.x]

3. Shulkin DJ. Cost estimates of diagnostic procedures. N Engl J Med 1988;319(19):1291. [http://dx.doi. org/10.1056/NEJM198811103191920]

14. Long MJ, Cummings KM, Frisof KB. Role of perceived price in physician demand for diagnostic tests. Med Care 1983;21(2):243-250. [http://dx.doi.org/10.1097/00005650-198302000-00011]

S Afr Med J 2015;105(8):618. DOI:10.7196/SAMJnew.7810 